\title{
Curcumin exhibits therapeutic effect against spinal cord injury via inhibition of neuronal inflammation and apoptosis
}

\author{
Wei Xiao', Xuewu Chen ${ }^{2}$, Yijun Wang ${ }^{2}$, Jianzhong Chang ${ }^{1}$, Zufa Zhao ${ }^{1}$, \\ Guangjie Pan ${ }^{2 *}$ \\ ${ }^{1}$ Department of Orthopaedic, China Resources \& Wisco General Hospital, Wuhan, Hubei 430080, ${ }^{2}$ Department of Orthopaedic, \\ Wenzhou Central Hospital, Wenzhou, Zhejiang 325000, China
}

*For correspondence: Email: JoshuaKhankyw@yahoo.com

\begin{abstract}
Purpose: To investigate the effect of curcumin on spinal cord injury (SCl) in a rat model.

Methods: SCl was induced in the rats using mid thoracic spinal cord compression, after which curcumin was injected intraperitoneally. Western blotting was used for assay of expressions of apoptotic proteins, viz, IL-1 $\beta, N F-K B$ p65, TLR4, TNF- $\alpha, L C 3, B a x$ and Bcl-2. Malondialdehyde (MDA) and myeloperoxidase were measured using standard methods. Neuronal loss in spinal cord tissues was determined with TUNEL staining and NeuN labelling.

Results: Curcumin treatment significantly $(p<0.05)$ suppressed SCl-mediated upregulation of myeloperoxidase activity and increase in MDA level in rat spinal cord. The reduction of glutathione (GSH) and superoxide dismutase (SOD) activities in the spinal cord of SCl rats were suppressed by curcumin treatment. Curcumin treatment also led to a significant $(p<0.02)$ increase in the proportion of NeuN positive cells and marked reduction in TUNEL positive cells, but it decreased caspase-3 in the spinal cord tissues of $\mathrm{SCl}$ rats. Moreover, curcumin reversed the effect of $\mathrm{SCl}$ on protein expressions of $B a x$ and $B C l 2$ in a dose-based manner. There was marked curcumin-induced decline in CD11b and GFAP levels in the spinal cord tissues of the SCl rats.

Conclusion: These results demonstrate that curcumin protects rats against $\mathrm{SCl}$ via inhibition of oxidative stress-mediated neuronal apoptosis. Therefore, curcumin may be useful for the development of an effective treatment for spinal cord injury.
\end{abstract}

Keywords: Curcumin, Spinal cord injury, Neuro-protective effect, Inflammatory cytokines

\begin{abstract}
This is an Open Access article that uses a fund-ing model which does not charge readers or their institutions for access and distributed under the terms of the Creative Commons Attribution License (http://creativecommons.org/licenses/by/4.0) and the Budapest Open Access Initiative (http://www.budapestopenaccessinitiative.org/read), which permit unrestricted use, distribution, and reproduction in any medium, provided the original work is properly credited.

Tropical Journal of Pharmaceutical Research is indexed by Science Citation Index (SciSearch), Scopus, International Pharmaceutical Abstract, Chemical Abstracts, Embase, Index Copernicus, EBSCO, African Index Medicus, JournalSeek, Journal Citation Reports/Science Edition, Directory of Open Access Journals (DOAJ), African Journal Online, Bioline International, Open-J-Gate and Pharmacy Abstracts
\end{abstract}

\section{INTRODUCTION}

Spinal cord injury (SCl) is caused by fracture in the vertebral column leading to irreversible mechanical injury [1]. It is generally caused either by mechanical factors or by trauma resulting in permanent loss of movement in the limb and trunk [2]. Spinal cord injury (SCl) is accompanied by a sequence of neuro-pathological events leading to imbalance in electrolyte concentrations, disruption in arterial blood supply, and thrombosis [1]. 
Secondary $\mathrm{SCl}$ is considered very harmful, relative to primary $\mathrm{SCl}$ because it causes degeneration of the nervous system [1]. Secondary $\mathrm{SCl}$ is worsened by the presence of inflammation, neuronal apoptosis and autophagy [3]. Efforts have been made to investigate the mechanism involved in $\mathrm{SCl}$ so as to develop effective treatments for the disease, but no success has been achieved so far [1-3]. Thus, there is need for more studies aimed at developing effective treatment for $\mathrm{SCl}$ without producing any harmful side effects.

Oxidative stress is a major factor in the development of secondary injury following $\mathrm{SCl}$ [4]. Reactive oxygen species (ROS) are produced by the membrane enzyme known as nicotinamide adenine dinucleotide phosphate (NADPH) oxidase [5]. Studies have shown that neurons, microglia and astrocytes express high level of NADPH oxidase [5]. It is well known that the production of ROS by NADPH oxidase is important in the modulation of nervous system function in pathological conditions [6]. Therefore, the inhibition of NADPH oxidase activity by chemotherapeutic agents is as an attractive target for the treatment of nervous system disorders [16].

In traditional system of medicine, curcumin has shown various pharmacological effects, with negligible or no side effects [7]. Studies have revealed that curcumin possesses antibacterial, anti-inflammatory, anti-oxidant, hypolipidemic and anti-fibrotic potential [7,8]. Moreover, curcumin prevents myocardial injury and inhibits tumor growth $[7,8]$. Inhibition of inflammationrelated gene expression by curcumin protects against myocardial injury through NF-kB pathway [9]. The present study was designed to investigate the effect of curcumin on spinal cord injury in a rat model of $\mathrm{SCl}$.

\section{EXPERIMENTAL}

\section{Animals and establishment of SCl model}

Eighty adult male Sprague-Dawley rats weighing $300-330 \mathrm{~g}$ were supplied by the Experimental Animal Centre of the Hebei United University (Tangshan, China). The rats were kept in animal house under controlled conditions of temperature $\left(23-25^{\circ} \mathrm{C}\right)$ and humidity $(55+5 \%)$, and exposed to $12 \mathrm{~h}$ light/12 $\mathrm{h}$ dark cycles, with ad libitum access to feed and drinking water. Approval for the animal experimental procedures was obtained from the Ethics Committee for Care and Use of animals, Hebei United University [10]. The well-established mid-thoracic spinal cord compression procedure was used for inducing $\mathrm{SCl}$ in the rats [10].

The rats were placed on temperature-controlled heating pads in prone positions after chloral hydrate anesthesia administration. A longitudinal incision was made on the dorsal side of each rat along the midline under completely sterilized conditions. After exposure of the paravertebral muscles, dissection was carried out carefully to expose the T6/T7 vertebrae. The spinal cord was exposed using laminectomy, and a force of $24 \mathrm{~g}$ was applied around the spinal cord in the mid-thoracic region for 1.5 min using aneurysm clip. The rats were again put onto the heating pads $\left(36{ }^{\circ} \mathrm{C}\right)$ for $5 \mathrm{~h}$ after the incisions were sutured.

\section{Treatment strategy}

The rats were assigned to eight groups (10 rats per group): normal control, untreated group and six curcumin-treated groups $(10,20,30,40,50$ and $60 \mathrm{mg} / \mathrm{kg}$ ). Rats in the normal control group were subjected to surgery but no force was applied around spinal cord in the mid-thoracic region. Curcumin at doses of 10, 20, 30, 40, 50 and $60 \mathrm{mg} / \mathrm{kg}$ was given to the rats through intraperitoneal route after $40 \mathrm{~min}$ of $\mathrm{SCl}$. The normal control and untreated rats were given normal saline alone. Five of the rats from each group were sacrificed on day 5 for determination of pathological changes, while the remaining 5 rats were kept for use in determination of locomotory changes.

\section{Measurement of myeloperoxidase and SOD activities}

In the spinal cord tissues of curcumin-treated rats, the activity of MPO was measured in accordance with the procedure reported earlier [11]. The excised spinal cord tissues were subjected to homogenization at pH 7.4 in $45 \mathrm{mM}$ potassium phosphate buffer. The homogenates were clarified through centrifugation at $4^{\circ} \mathrm{C}$ for 15 $\min$ at $3,000 \mathrm{~g}$, and the pellets were treated with potassium phosphate buffer $(45 \mathrm{mM})$ and $0.5 \%$ $\mathrm{C}_{16} \mathrm{H}_{33}\left(\mathrm{CH}_{3}\right)_{3} \mathrm{NBr}$. The resultant suspension was then subjected to freeze and thaw cycles under sonication, and subsequently centrifuged for 15 $\min$ at $4^{\circ} \mathrm{C}$ at $3,000 \times \mathrm{g}$.

The supernatants were then reacted with a solution of $o$-dianisidine, potassium phosphate $(45 \mathrm{mM})$ and hydrogen peroxide (20 mM). Absorbance was measured spectrophotometrically at $475 \mathrm{~nm}$, and MPO activity was calculated and expressed in $\mathrm{U} / \mathrm{g}$. The SOD activity was measured in spinal cord tissues of 
$\mathrm{SCl}$ rats using the xanthine-xanthine oxidase procedure [11]. In this case, absorbance was read at a wavelength of $565 \mathrm{~nm}$ in a UV-2100 spectrophotometer (Shimadzu, Co., Ltd., Shanghai, China) in accordance with the manual protocol.

\section{Determination of MDA and GSH}

The spinal cord tissues of $\mathrm{SCl}$ rats were homogenized in potassium chloride (160 mM) under ice-cold conditions, and the homogenates were reacted with thiobarbituric acid to form a pink chromogen. The absorbance of the chromogen was read at $545 \mathrm{~nm}$, and the tissue level of MDA was calculated and expressed in $\mathrm{nmol} / \mathrm{g}$. Commercially available Cayman kit (Cayman, Ann Arbor, MI, USA) was used for the assessment of GSH level in the spinal cord tissues. The GSH levels were expressed in $\mathrm{mmol} / \mathrm{g}$.

\section{Histopathological examination of spinal cord tissues}

Changes in histology of $\mathrm{SCl}$ spinal cord tissues after curcumin treatment were determined using NeuN labelling and staining with terminal deoxynucleotidyl-transferase-mediated dUTP nick end labeling (TUNEL). The rats were anesthetized on day 5, and transcardially perfused with $4 \%$ paraformaldehyde. Then, 6$\mathrm{mm}$ tissue sample was excised from the injury site of the spinal cord and suspended in $4 \%$ paraformaldehyde for $24 \mathrm{~h}$. The tissue sample was then transferred to a solution of sucrose in PBS (30\%), and subsequently sliced axially into $25-\mu \mathrm{m}$ sections.

Tissue permeabilization was carried out using Triton X-100 (0.4\% solution), followed by incubation at room temperature with $5 \%$ donkey serum for $1.5 \mathrm{~h}$. Thereafter, the tissues were incubated overnight with monoclonal antibodies against NeuN at a temperature of $4^{\circ} \mathrm{C}$. Then, sections were subjected to $1 \mathrm{~h}$ incubation with anti-mouse IgG secondary antibodies at room temperature. Then, the spinal cord tissues were subjected to TUNEL staining by incubation with TdT enzyme and TMR red labelled dUTP in the dark. The incubation was carried out at $37^{\circ} \mathrm{C}$ for $1.5 \mathrm{~h}$, followed by washing two times for $15 \mathrm{~min}$, and visualization using converter-POD along with 3,3'-diaminobenzidine $(0.03 \%)$. Laser scanning confocal microscope (Olympus FluoView ${ }^{\mathrm{TM}}$ FV1000; Olympus Corporation, Tokyo, Japan) was used for detection of immunofluorescence. The surviving and TUNEL-positive neurons were quantified with Scion Image 4.02 (Scion Corporation, Boston, MA, USA).

\section{Western blot analysis}

The spinal cord tissues were homogenized in pre-cold lysis buffer (BioSource International Inc.; Thermo Fisher Scientific, Inc., Waltham, MA, USA) containing protease inhibitor cocktail (0.01\%; Sigma-Aldrich; Merck KGaA, Darmstadt, Germany). The tissue samples were then centrifuged at $12,000 \mathrm{~g}$ at $4^{\circ} \mathrm{C}$ for $20 \mathrm{~min}$., and the protein concentrations in the spinal cord tissue supernatants were determined using BCA kit (Solarbio, Beijing, China). Protein samples

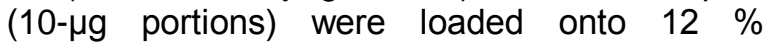
SDS-PAGE gel.

Following electrophoresis, the proteins were transferred to PVDF membrane, and non-specific binding sites were blocked with fat-free dry milk (5\%) for $1.5 \mathrm{~h}$. The blots were subjected to overnight incubation at $4{ }^{\circ} \mathrm{C}$ with primary antibodies against IL-1 $\beta$, NF-kB p65, TLR4, TNF$\alpha$, LC3, Bax and Bcl-2 (Santa Cruz Biotechnology, Inc.). Then, the blots were incubated for $1.5 \mathrm{~h}$ at room temperature with horseradish peroxidase conjugated secondary antibody (anti-rabbit lgG). The blots were developed for visualization using enhanced chemiluminescence (ECL) detection system.

\section{Plane of inclination test}

The ability of the SCI rats to balance on wooden beams at elevated positions after curcumin treatment was measured using the modified Rivlin's method [12]. The device used consisted of a plate which could be adjusted at an angle ranging from $0-90^{\circ}$. The balancing ability of each rat was recorded on days $2,4,6,8,10,12$ and 14 post-SCl. The rats were placed on the plate with head facing forward and the angle of inclination was gradually increased over a period of $5 \mathrm{sec}$ until the rats became uncomfortable in maintaining a constant position. The value of the critical angle for each rat was recorded.

\section{Determination of motor function recovery}

The Basso, Beattie and Bresnahan scoring system was used to determine hind limb recovery in $\mathrm{SCl}$ rats following curcumin treatment. This system uses a 21-point scale for measuring recovery potential after SCI [13]. In this scoring system, perfectly healthy rats score 21 points, while those with complete paralysis of the hind limbs score 0 . The rats were forcibly made to walk for 20 min in the open field on days 2, 4, 6, 8, 10, 12 and 14 post-SCl, and the movements of hind limb were monitored by two observers naïve to the test, who recorded the BBB scores. 


\section{Statistical analysis}

Data are presented as mean $\pm S D$ of three measurements. The SPSS 16.0 statistics software (SPSS, Inc., Chicago, IL, USA) was employed for the statistical analysis using one-way analysis of variance (ANOVA), followed by Student-Newman Keuls post hoc tests. Values of $p<0.05$ were taken to indicate statistically significant differences.

\section{RESULTS}

\section{Curcumin suppressed production of oxidative stress molecules in rats with $\mathrm{SCl}$}

The spinal cord tissues of SCl rats had significantly $(p<0.05)$ higher activity of myeloperoxidase and higher MDA level than those of the normal control group (Figure 1). Treatment of $\mathrm{SCl}$ rats with curcumin at doses of $10,20,30,40,50$ and $60 \mathrm{mg} / \mathrm{kg}$ significantly suppressed the myeloperoxidase activity and reduced MDA levels in spinal cord tissue. Results from measurement of antioxidant levels revealed that GSH and SOD contents were decreased significantly $(p<0.02)$ in the $\mathrm{SCl}$ rats (Figure 1). In the spinal cord tissues of $\mathrm{SCl}$ rats, treatment with curcumin prevented reductions in GSH levels and SOD activity.

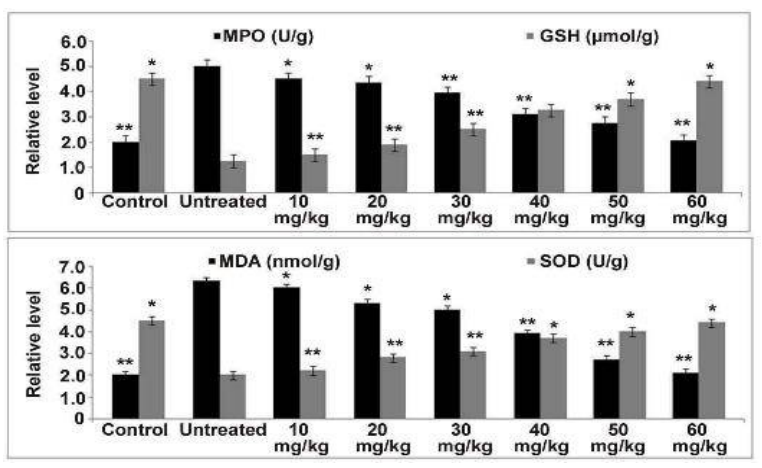

Figure 1: Effect of curcumin on oxidative and antioxidant molecules. In the $\mathrm{SCl}$ rats, treatment with curcumin at doses of 10,20,30,40,50 and $60 \mathrm{mg} / \mathrm{kg}$ was followed by measurement of myeloperoxidase activity, glutathione content, level of MDA, and SOD activity. The values are expressed as mean \pm SD of triplicate measurements. ${ }^{*} p<0.05 ;{ }^{* *} p<0.02$, relative to negative control rat group

\section{Curcumin treatment prevented neuronal injury}

In the SCl rats, a significant $(p<0.05)$ decrease was observed in neuronal count, when compared to rats in the normal control group (Figure 2). The population of cells showing NeuN-positive staining was low in $\mathrm{SCl}$ rats, but there was a significant increase in the percentage of TUNEL-positive cells in these rats $(p<0.02)$, relative to normal rats. However, curcumin treatment caused significant and dosedependent increases in the proportion of $\mathrm{NeuN}$-positive cells in $\mathrm{SCl}$ rat spinal cord tissues $(p<0.02)$.

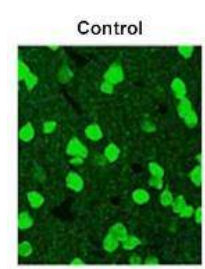

$30 \mathrm{mg} / \mathrm{kg}$

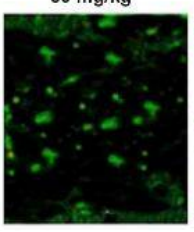

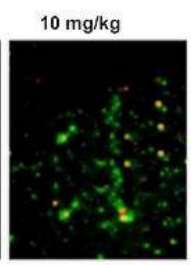

$50 \mathrm{mg} / \mathrm{kg}$
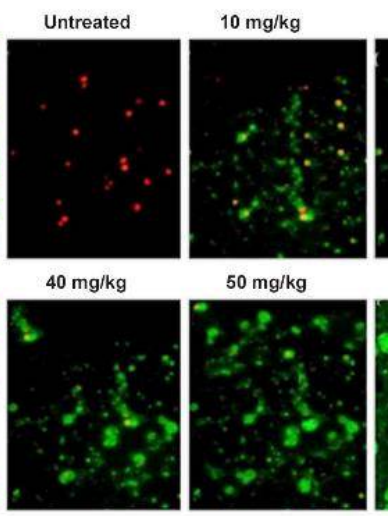

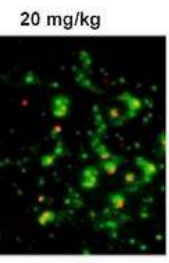

$60 \mathrm{mg} / \mathrm{kg}$

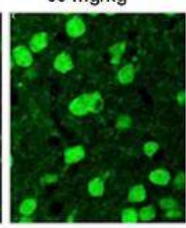

Figure 2: Effect of curcumin on neuronal count in SCI rats. Spinal cord tissues of $\mathrm{SCI}$ rats were subjected to NeuN- labelling after curcumin treatment (x250)

Curcumin treatment also led to a significant $(p<$ 0.02 ) reduction in the population of TUNEL-positive cells in the spinal cord of SCl rats (Figure 3). The treatment brought about significant and dose-dependent decreases in the proportion of TUNEL-positive cells in the $\mathrm{SCl}$ rats.

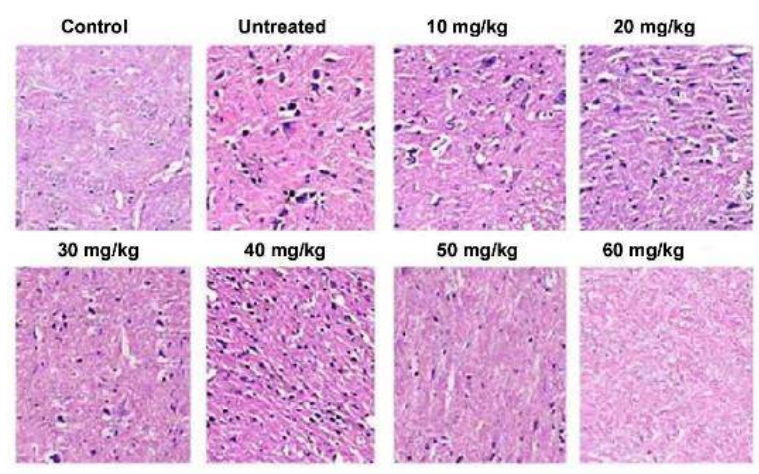

Figure 3: Effect of curcumin on neuronal apoptosis in $\mathrm{SCl}$ rats. The spinal cord tissues of $\mathrm{SCl}$ rats were subjected to TUNEL staining after curcumin treatment (x 250)

\section{Curcumin suppressed apoptotic protein expression in $\mathrm{SCl}$ rats}

The level of activated caspase- 3 in the spinal cord tissues of rats was increased significantly following SCl (Figure 4). However, curcumin treatment prevented $\mathrm{SCl}$-induced increase in the level of caspase-3 in spinal cord tissues of the rats. Curcumin treatment caused dosedependent decreases in the level of caspase- 3 in 
the $\mathrm{SCl}$ rat tissues. In the rat spinal cord tissues, $\mathrm{Bax}$ was upregulated, while $\mathrm{Bcl}-2$ was downregulated following SCl. However, treatment of the $\mathrm{SCl}$ rats with curcumin reversed the effect of $\mathrm{SCl}$ on the protein expressions of $\mathrm{Bax}$ and $\mathrm{Bcl}-2$ in a dose-based manner. In SCl rats treated curcumin at a dose of $60 \mathrm{mg} / \mathrm{kg}$, there were no significant differences in the protein expressions of $\mathrm{Bax}$ and $\mathrm{Bcl}-2$ proteins, when compared to those of the normal control group.

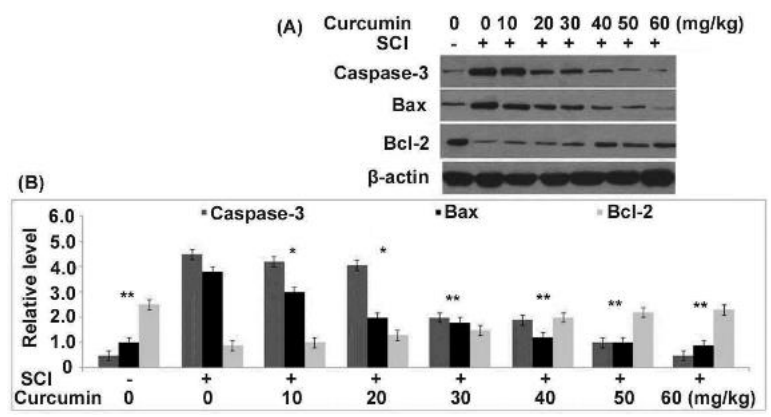

Figure 4: Effect of curcumin on apoptotic protein expressions. (A) Protein expression levels in spinal cord tissues, as determined using western blotting. (B) Quantification of protein expression data. Values are expressed as mean $\pm \mathrm{SD}$, with $\beta$-actin as loading control; ${ }^{*} p<0.05$; ${ }^{* *} p<0.02$, compared with negative control group

\section{Curcumin reduced $\mathrm{SCl}$-mediated release of inflammatory cytokines}

The spinal cord tissues of $\mathrm{SCl}$ rats showed markedly higher level of staining for CD11b and GFAP than those of the normal control group (Figure 5). The marked decreases in CD11b and GFAP levels were caused by curcumin treatment in the spinal cord tissues of $\mathrm{SCl}$ rats. The spinal cord tissues of $\mathrm{SCl}$ rats also showed significantly higher contents of interleukin- $6 /-1 \beta$ and TNF- $\alpha$ ( $p$ $<0.02$ ) than those in the normal control group. Treatment of the SCI rats with curcumin lead to marked reductions in the secretions of interleukin-6/-1 $\beta$ and TNF- $\alpha$ in spinal cord tissues, when compared to untreated rats.

\section{Protective effect of curcumin on spinal cord motor function}

Following $\mathrm{SCl}$, the rats scored lower in the plane inclination test and in BBB-test than rats in the normal control group (Figure 6). However, treatment of the $\mathrm{SCl}$ rats with curcumin caused significant increases in the plane inclination and BBB-test scores, when compared to the untreated rats. These findings demonstrated that curcumin prevented SCl-induced damage to motor function in the rats.

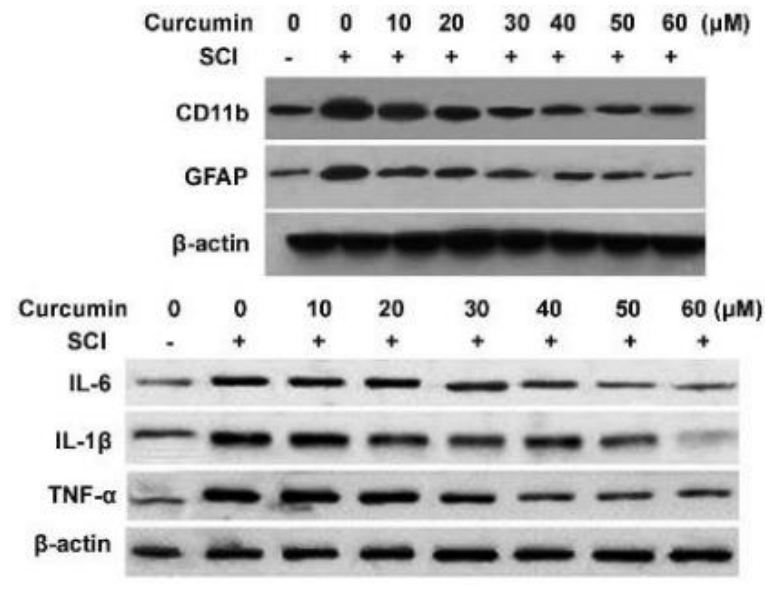

Figure 5: Effect of curcumin on cytokine secretion. Changes in levels of CD11b, GFAP and cytokines due to curcumin treatment were determined using western blotting

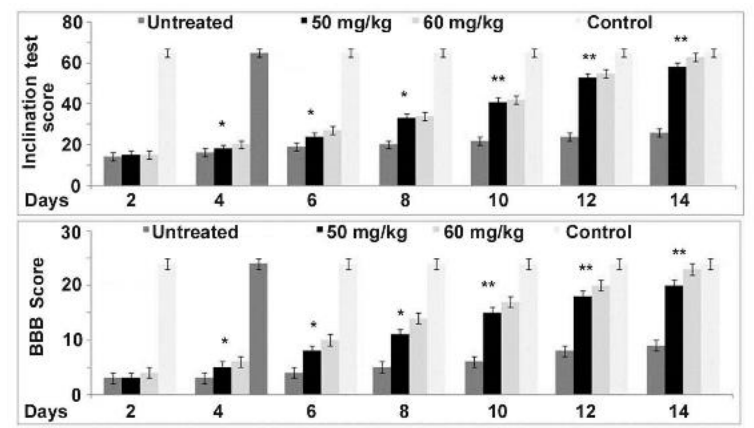

Figure 6: Effect of curcumin treatment on motor function damage in $\mathrm{SCl}$ rats. Following curcumin treatment, the $S C I$ rats were subjected to $(A)$ inclined plane test, and (B) BBB-test on days 2, 4, 6, 8, 10, 12 and 14 post-SCI. The data presented are mean of three measurements. ${ }^{\star} p<0.05 ;{ }^{* *} p<0.02 ;{ }^{* \star *} p<$ 0.01 , relative to negative control group

\section{DISCUSSION}

The present study was designed to investigate the role of curcumin in the protection of neuronal damage and prevention of spinal cord injury in $\mathrm{SCl}$ rats. The study demonstrated that curcumin prevented neuronal apoptosis through downregulation of inflammatory cytokine production in the spinal cord tissues. Curcumin prevented loss of locomotion function in the $\mathrm{SCl}$ rats, as was evident in the higher scores in inclined plane test and BBB-test. Direct mechanically- or traumainduced $\mathrm{SCl}$ is always accompanied by secondary injury which leads to the loss of neurons [14].

Studies have revealed that development of secondary $\mathrm{SCl}$ involves complicated network of signalling pathways [15]. Oxidative stressinduced neuronal damage after $\mathrm{SCl}$ is the main factor responsible for development of secondary 
injury [16]. Therefore, it is believed that downregulation of oxidant molecules and up-regulation of anti-oxidant factors are important in the inhibition of secondary SCl. In the present study, the effect of curcumin on expression of myeloperoxidase was investigated. Myeloperoxidase is abundantly expressed in neutrophils and monocytes. The results showed that $\mathrm{SCl}$ increased myeloperoxidase expression in the spinal cord tissues, but this increase was reversed by curcumin treatment. In SCl rats, the level of MDA was also increased significantly.

However, treatment of the $\mathrm{SCl}$ rats with curcumin markedly suppressed the level of MDA, when compared to the untreated group. There were marked decreases in GSH level and SOD activity in the rats by $\mathrm{SCl}$. Reduced glutathione (GSH) and SOD suppress oxidative damage by scavenging free radicals. Treatment of the rats with curcumin prevented SCl-mediated reduction in GSH and SOD in spinal cord tissues. Therefore, curcumin reduced the expressions of oxidative protein molecules and promoted the level of antioxidants.

The development of secondary $\mathrm{SCl}$ is also associated with the secretion of inflammatory cytokines through MAPK pathway activation [15]. Accumulation of microglia during $\mathrm{SCl}$ leads to the inflammatory reactions by enhancing the release of interleukin-6/1 $\beta$ and TNF- $\alpha$ [17]. During the initial stage of $\mathrm{SCl}$, various molecules like GFAP and nerve growth factor are produced by the astrocytes in relation to the neuronal damage [18]. Studies involving mice have shown that SCI markedly enhances the production of inflammatory cytokines [19].

The level of GFAP is an indication of the degree of damage to the neurons following $\mathrm{SCl}$. In the present study, treatment of the rats with curcumin suppressed SCl-mediated increases in the production of CD11b and GFAP. In addition, treatment of the $\mathrm{SCl}$ rats with curcumin caused marked reductions in the levels of interleukin$6 / 1 \beta$ and TNF- $\alpha$ in the spinal cord tissues. During secondary $\mathrm{SCl}$, there is a marked decrease in the population of neurons due to apoptosis [20]. Neuronal apoptosis during secondary $\mathrm{SCl}$ is characterized by increased level of caspase-3 [21].

The results from the present showed markedly high level of caspase-3 in the spinal cord tissues of $\mathrm{SCl}$ rats. However, treatment of the $\mathrm{SCl}$ rats with curcumin caused a significant reduction in caspase-3 level. Moreover, the proportion of TUNEL-positive cells in the spinal cord tissues of the $\mathrm{SCl}$ rats was markedly decreased on treatment with curcumin. Apoptosis onset is promoted by the expression of Bax through oxidative stress, whereas $\mathrm{Bcl}-2$ opposes apoptosis by suppressing mitochondrial permeability [22]. In the present study, treatment of the $\mathrm{SCl}$ rats with curcumin reduced $\mathrm{Bax}$ expression, and increased $\mathrm{Bcl}-2$ levels. In the inclined plane and BBB tests, rats treated with curcumin scored significantly higher than those in the $\mathrm{SCl}$ group. These findings suggest that curcumin prevented damage to neurological tissues and reversed movement dysfunction in $\mathrm{SCl}$ rats through inhibition of neuronal loss and inflammation.

\section{CONCLUSION}

The present study demonstrates that curcumin protects rats against $\mathrm{SCl}$ via inhibition of oxidative stress-mediated neuronal apoptosis. Therefore, curcumin is a potential medicinal agent for the management of spinal cord injury.

\section{DECLARATIONS}

\section{Conflict of interest}

No conflict of interest is associated with this work.

\section{Contribution of authors}

We declare that this work was done by the authors named in this article and all liabilities pertaining to claims relating to the content of this article will be borne by the authors. Guangjie Pan designed the study and wrote the paper. Wei Xiao, Xuewu Chen, Yijun Wang and Jianzhong Chang performed the experimental work, Zufa Zhao and Guangjie Pan carried out the literature study and compiled the data. Wei Xiao and Xuewu Chen performed literature survey, analyzed and compiled the data. The research article was thoroughly read by all the authors.

\section{Open Access}

This is an Open Access article that uses a funding model which does not charge readers or their institutions for access and distributed under the terms of the Creative Commons Attribution License (http://creativecommons.org/licenses/by/ 4.0) and the Budapest Open Access Initiative (http://www.budapestopenaccessinitiative.org/rea d), which permit unrestricted use, distribution, and reproduction in any medium, provided the original work is properly credited. 


\section{REFERENCES}

1. Fehlings MG, Perrin RG. The role and timing of early decompression for cervical spinal cord injury: update with a review of recent clinical evidence. Injury 2005; 36 : B13-B26.

2. Grigorean VT, Sandu AM, Popescu M, lacobini MA, Stoian R, Neascu C, Strambu V, Popa F. Cardiac dysfunctions following spinal cord injury. J Med Life 2009; 2: 133145.

3. Walker CL, Walker MJ, Liu NK, Risberg EC, Gao X, Chen $J, \quad X U X M$. Systemic bisperoxovanadium activates Akt/mTOR, reduces autophagy and enhances recovery following cervical spinal cord injury. PLoS One 2012; 7: e30012.

4. Khayrullina G, Bermudez S, Byrnes KR. Inhibition of NOX2 reduces locomotor impairment, inflammation, and oxidative stress after spinal cord injury. $J$ Neuroinflammation 2015; 12: 172.

5. Bedard $K$, Krause $K H$. The NOX family of ROS generating NADPH oxidases: Physiology and pathophysiology. Physiol Rev 2007; 87: 245313.

6. Lo W, Bravo T, Jadhav V, Titova E, Zhang JH, Tang J. $N A D P H$ oxidase inhibition improves neurological outcomes in surgically induced brain injury. Neurosci Lett 2007; 414: 228232.

7. Qian $Y$, Zhong $P$, Liang $D, X u Z$, Skibba M, Zeng C, Li X, Wei $T$, Wu L, Liang G.A newly designed curcumin analog Y20 mitigates cardiac injury via anti-inflammatory and anti-oxidant actions in obese rats. PLoS One 2015; 10: e0120215.

8. Patel PB, Thakkar VR, Patel JS. Cellular effect of curcumin and citral combination on breast cancer cells: Induction of apoptosis and cell cycle arrest. J Breast Cancer 2015; 18: 225234.

9. Yeh $\mathrm{CH}$, Chen TP, Wu YC, Lin YM, Jing Lin P. Inhibition of NFkappaB activation with curcumin attenuates plasma inflammatory cytokines surge and cardiomyocytic apoptosis following cardiac ischemia/reperfusion. J Surg Res 2005; 125: 109116.

10. Rivlin A, Tator $\mathrm{CH}$. Effect of duration of acute spinal cord compression in a new acute injury model in the rat. Surg Neurol 1978; 10: 3843.

11. Hillegass $L M$, Griswold DE, Brickson B, Albrightson Winslow C. Assessment of myeloperoxidase activity in whole rat kidney. J Pharmacol Methods 24: 285 295, 1990.

12. Rivlin AS and Tator $\mathrm{CH}$ : Objective clinical assessment of motor function after experimental spinal cord injury in the rat. J Neurosurg 1977; 47: 577581.

13. Basso DM, Beattie MS, Bresnahan JC. A sensitive and reliable locomotor rating scale for open field testing in rats. J Neurotrauma 1995; 12: 121.

14. Blight AR. Morphometric analysis of blood vessels in chronic experimental spinal cord injury: Hypervascularity and recovery of function. J Neurol Sci 1991; 2: 158174.

15. Song $Y$, Liu J, Zhang $F$, Zhang J, Shi T, Zeng $Z$. Antioxidant effect of quercetin against acute spinal cord injury in rats and its correlation with the p38MAPK/iNOS signaling pathway. Life Sci 2013; 92: 12151221.

16. Juurlink BH, Paterson PG. Review of oxidative stress in brain and spinal cord injury: Suggestions for pharmacological and nutritional management strategies. J Spinal Cord Med 1998; 21: 309334.

17. Fehlings MG, Nguyen DH. Immunoglobulin G: A potential treatment to attenuate neuroinflammation following spinal cord injury. J Clin Immunol 2010; 30 (Suppl 1): S109 S112.

18. Faulkner JR, Herrmann JE, Woo MJ, Tansey KE, Doan $N B$, Sofroniew MV. Reactive astrocytes protect tissue and preserve function after spinal cord injury. J Neurosci 2004; 24: 21432155.

19. Impellizzeri D, Esposito E, Mazzon E, Paterniti I, Di Paola $R$, Bramanti P, Morittu VM, Procopio A, Perri E, Britti D, Cuzzocrea $S$. The effects of a polyphenol present in olive oil, oleuropein aglycone, in an experimental model of spinal cord injury in mice. Biochem Pharmacol 2012; 83: 14131426.

20. Rong W, Wang J, Liu X, Jiang L, Wei F, Hu X, Han X, Liu $Z$. Naringin treatment improves functional recovery by increasing BDNF and VEGF expression, inhibiting neuronal apoptosis after spinal cord injury. Neurochem Res 2012; 37: 16151623.

21. Wei H, Teng H, Huan W, Zhang S, Fu H, Chen F, Wang J, Wu C, Zhao J. An upregulation of SENP3 after spinal cord injury: Implications for neuronal apoptosis. Neurochem Res 2012; 37: 27582766.

22. Dlugosz PJ, Billen LP, Annis MG, Zhu W, Zhang Z, Lin J, Leber $B$, Andrews DW. Bcl 2 changes conformation to inhibit Bax oligomerization. EMBO J 2006; 25: 2287 2296. 